\title{
O BANHEIRO COMO ESPAÇO POLÍTICO DE GÊNERO ${ }^{1}$
}

\author{
THE BATHROOM AS A POLITICAL SPACE OF GENDER
}

EL BAÑO COMO ESPACIO POLÍTICO DE GÉNERO

\author{
DIAS, Alfrancio Ferreira2 ${ }^{2}$ \\ ZOBOLI, $\mathrm{Fabio}^{3}$ \\ SANTOS, Adriana Lohanna dos ${ }^{4}$
}

\section{RESUMO}

Os usos do corpo implicam uma territorialização política dos espaços. Posto isso, o presente artigo objetiva, a partir dos corpos de estudantes transexuais da Universidade Federal de Sergipe (UFS), analisar o banheiro como espaço político de gênero, por meio de um estudo qualitativo com base em entrevistas narrativas feitas com sete estudantes transexuais de cursos de graduação da UFS. Como resultado, tem-se a percepção de que estudantes transexuais lidam com dificuldades, situações de preconceito e, além disso, precisam encontrar estratégias para utilizar o banheiro na universidade. Frente aos resultados da pesquisa, visualiza-se a necessidade da superação da demarcação e governo de gênero pautada numa política que não mais estabeleça um sujeito de identidade fixa, mas que abarque a pluralidade dos corpos.

Palavras-chave: Corpo. Gênero. Política. Transexualidade.

\section{ABSTRACT}

The uses of the bodies involve a political territorialisation of the spaces. That being said, the present article aims, from the transexual students bodies at the Federal University of Sergipe (UFS), to analyze the bathroom like political gender space, through a qualitative study on basis of narrative interviews done with seven transexual students of degree courses of the UFS. As result, there is a belief that transexual students deal with difficulties, prejudice situations and, besides, they need to find strategies to use the bathroom in the university. In front of the results of the research, is possible to visualize the necessity of the overcoming of the demarcation and gender government ruled on a policy that not more establishes a subject of fixed identity, but that comprises the plurality of the bodies.

Keywords: Body. Gender. Policy. Transsexuality.

\section{RESUMEN}

Los usos del cuerpo implican una territorialización política de los espacios. Dicho eso, el presente artículo objetiva, a partir de los cuerpos de estudiantes transexuales de la Universidad Federal de Sergipe (UFS), analizar el cuarto de baño como espacio político de género, a través de un estudio cualitativo basado en entrevistas narrativas realizadas con siete estudiantes transexuales de los cursos de graduación de UFS. Como resultado, se tiene la percepción de que los estudiantes transexuales se enfrentan a dificultades, situaciones de prejuicio y, además, necesitan encontrar estrategias para utilizar el baño en la universidad. Frente a los resultados de la investigación, se visualiza la necesidad de la superación de la demarcación y gobierno de género pautada en una política que ya no establezca un sujeto de identidad fija, sino que abarque la pluralidad de los cuerpos.

Palabras clave: Cuerpo. Género. La política. Transexualidad.

\footnotetext{
1 Pesquisa financiada pelo CNPq através da Chamada 01/2016 - Universal.

2 Universidade Federal do Sergipe - UFS - São Cristóvão - Sergipe - Brasil.

3 Universidade Federal do Sergipe - UFS - São Cristóvão - Sergipe - Brasil.

${ }^{4}$ Rede Municipal de Educação de Lagarto - Sergipe - Brasil.
} 


\section{INTRODUÇÃO}

A política pode ser pensada de forma ampla, como a gestão e regulação dos comportamentos responsáveis por produzirem mediadores que determinam conteúdos e formas para as relações humanas. Isso significa que a política se realiza por meios e fins jurídicos e morais dos quais o Estado e o Direito se ocupam em termos antropológicos, como evidenciam os textos clássicos da política. As teorias do Estado se pautam em discussões filosóficas da arte/ciência de governar a partir dos comportamentos intersubjetivos intercambiados nos mais diversos contextos culturais. Conforme Milner (2013), a gestão do comportamento humano está materialmente inscrita e suportada pelos corpos regulados por regras e valores culturalmente relativos que, em última instância, implicam técnicas corporais e, em meio à pluralidade dos seres falantes 5 (massa/população), tentam impor algum tipo de limite para definir comportamentos adequados dentro de uma sociedade organizada para além das vontades individuais.

O corpo é um território de fronteiras que articula a sua materialidade tanto por meio de traços físicos ou características observáveis como pelos traços demarcados pela linguagem que dá a ele uma capacidade de representação simbólica. Essa dupla capacidade se dá por dispositivos que o atravessa num contexto cultural permeado por uma rede de signos/linguagens que vão embotando sentido e legitimação às suas formas de governo.

Pensar tais questões sob a perspectiva do gênero e da sexualidade é pensar historicamente como o pênis e a vagina - enquanto signos fronteiriços - demarcaram as pessoas a partir de uma estrutura biológica. Essas demarcações distintivas materiais, por extensão, demarcaram também o corpo de forma simbólica, pois as categorias de gênero e sexualidade gestam políticas e estéticas mediadas por agenciamentos históricos de subjetivação, na medida em que, além de ter um pênis ou uma vagina, o sujeito deve internalizar os conteúdos e as formas de relacionamentos, existentes na sociedade, entre os sujeitos, conforme suas diferenças e semelhanças corporais.

Conforme Butler (2002, p. 39-40), 'La condición indiscutida del 'sexo' dentro de la díada heterosexual afirma las acciones de ciertos mandatos simbólicos y que oponerse a ella cuestiona donde y cómo se fijan los límites de la inteligibilidade simbólica”. Assim, historicamente, são sujeitos subjetivados e (re)produtores da/pela heteronormatividade. Adequam-se às normas sociais de gênero e corporificam uma inteligibilidade de gênero pautada a partir da tríade sexo (homem $\mathrm{x}$ mulher) gênero (masculino $x$ feminino) - heterossexualidade (orientação do desejo sexual por pessoas do sexo oposto) (CARVALHO et al., 2016), ou seja, tornam-se sujeitos compreensíveis, com corpos invisíveis e educados por uma pedagogia de gênero e de sexualidade da anulação. Os corpos transexuais rasgam, borram ou subvertem a heterossexualização compulsória, produzidas pela tríade sexo-gêneroheteronormatividade, propondo (des) aprendizagens e problematizações acerca das experiências de ser e estar no mundo.

\footnotetext{
${ }^{5}$ Aristóteles se refere ao homem como ser político pois é um animal que fala, por isso as expressões de seres falantes nesse texto.
} 
Este estudo soma-se a outras produções ligadas a temática da transexualidade no campo da Educação. Bento (2014) em seu estudo constata um aumento de publicações relacionadas ao tema nos últimos 10 anos e pressupõe que esse acréscimo pode estar relacionado ao fenômeno da maior presença de pessoas transexuais no contexto universitário, seja na condição de estudantes, docentes ou assumindo outras funções.

Ao sistematizar a literatura que versa sobre questões relacionadas à Transexualidade e Educação, na grande área das Ciências Humanas, em periódicos cadastrados na plataforma Sucupira (Qualis/CAPES A1 e A2 - no período de 2012-2016), pode-se perceber que a produção do conhecimento analisada apresenta efeitos significativos, indicando que a discussão sobre a transexualidade no campo da educação propõe desestabilizações as normas de gênero pautadas na heteronormatividade, possibilitando novas estratégias, atitudes, procedimentos pedagógicos subversivos e de negociação no campo da educação (TORRES; PRADO, 2014; LONGARAY; RIBEIRO, 2015; SILVA JUNIOR, 2016; SEFFNER; REIDEL, 2015; DIAS; CARVALHO; OLIVEIRA, 2016; FRANCO; CICLINI, 2015; JAEKEL; NICOLAZZO, 2017; NICOLAZZO, 2017).

Este resultado está em consonância com questões apontadas a partir da análise de dissertações e teses publicadas no Banco de Teses da CAPES. Percebe-se nesses estudos que a identidade Transexual é reflexionada a partir das trajetórias e memorias escolares (escolarização formal) de estudantes transexuais; dificuldades de acesso e a permanência de estudantes transexuais nas instituições de ensino; e, professoras transexuais na educação básica (ANDRADE, 2012; REIDEL, 2013; FRANCO, 2014; SANTOS, 2018).

Os resultados das pesquisas em ambos os estudos demostram que o tema da transexualidade potencializa a reflexão sobre o campo da educação como campo político, abrindo e reabrindo as reflexões sobre os corpos dissidentes, propondo questões sobre "lugares" e "fazeres" nas relações diárias. Ou seja, os corpos trans passam a fazer e desfazer o gênero e a sexualidade no cotidiano dos espaços formativos, como um ato de negociação de gênero (PEREIRA, 2012).

Frente a isso, o objetivo do presente artigo é analisar o banheiro como espaço político de gênero, a partir dos corpos de estudantes transexuais da Universidade Federal de Sergipe (UFS). Como afirma Preciado (2014), os contextos sexuais se estabelecem por meio de delimitações espaçotemporais oblíquas. A arquitetura dos usos corporais é política. É ela que organiza as práticas e as qualifica.

A fim de se desvelar tal problemática, o texto é organizado a partir de quatro partes: em um primeiro momento, é apresentado o gênero como política de governo dos corpos; na segunda parte, disserta-se sobre a metodologia e os sujeitos da pesquisa; na sequência, os dados são tensionados sob a ótica pós-estruturalista de gênero. Por fim, na última parte do escrito são apresentadas as considerações finais. 


\section{O GÊNERO ENQUANTO TECNOLOGIA POLÍTICA}

Qual é o gênero de uma pessoa trans? Eis uma pergunta que muitas pessoas fazem, mas dificilmente é respondida, posto que a existência de um corpo trans na sociedade questiona a hegemonia heterossexual, a cisgeneridade ${ }^{6}$ e o modo de ver e perceber a construção de gênero pelas pessoas, pois traz à tona algo diferente do que a norma heterossexual (re)produz.

Vive-se em uma sociedade onde os termos "menino", "menina", "homem", "mulher", "masculino" e "feminino" permeiam o universo das vidas antes mesmo do nascimento. Corpos que são "encaixados" em estereótipos e demarcadores de gênero são, também, condicionados a partir da ideia de que a "sexualidade normal e natural é a heterossexual" (BENTO, 2008, p. 33). Neste processo, os corpos são demarcados e possuir um gênero significa ter entrado numa relação heterossexual de subordinação (BUTLER, 2014), incorporando maneiras e formas de vivências constituídas a partir da relação de poder exercida em nossos corpos através dessa demarcação. Assim, o corpo trans, por não seguir esse binarismo heterossexual, transcende e foge à regra desse processo de identidade social.

Segundo Scott (1985, p.86), o gênero é "um elemento constitutivo de relações sociais baseadas nas diferenças percebidas entre os sexos e (...) uma forma primária de dar significado às relações de poder". Aqui, parte-se da compreensão de que gênero e sexo não são sinônimos, sendo o sexo o aparelho genital e gênero uma "tecnologia sofisticada que fabrica corpos sexuais" (PRECIADO, 2014, p.29).

A natureza humana é um efeito da tecnologia social que reproduz nos corpos, nos espaços e nos discursos a equação: natureza = heterossexualidade. O sistema heterossexual é um dispositivo social de produção de feminilidade e masculinidade que opera por divisão e fragmentação do corpo: recorta órgãos e gera zonas de alta intensidade sensitiva e motriz (visual, tátil, olfativa...) que depois identifica como centros naturais e anatômicos da diferença sexual (PRECIADO 2014, p. 25).

Conforme Miskolci (2013, p. 46-47), a heteronormatividade ou cisnormatividade é a "ordem sexual do presente, fundada no modelo heterossexual, familiar e reprodutivo. Ela se impõe por meio de violências simbólicas e físicas, dirigidas principalmente a quem rompe as normas de gênero". Nesse contexto, ao colocar e definir a cisnormatividade, Vergueiro (2015, p. 57) menciona que:

O conceito de cisnormatividade pode estar englobado pelo conceito butleriano de
heteronormatividade: ao definir as identidades de gênero ininteligíveis - ou cuja existência é
afronta a normatividades - como "aquelas em que o gênero não decorre do sexo e aquelas em
que as práticas do desejo não 'decorrem' nem do 'sexo' nem do 'gênero'”, e a identidade de
gênero como "uma relação entre sexo, gênero, prática sexual e desejo".

Portanto, os corpos que contradizem a cisheteronormatividade são vítimas de vigilância e coerção por parte da sociedade. A heterossexualidade é também uma construção social, pode-se

\footnotetext{
${ }^{6}$ Podemos entender como cisgeneridade, a identidade de gênero das pessoas, onde a experiência interna e individual do seu gênero está em consonância com o sexo atribuído em seu nascimento.
} 
entender que há outras possibilidades de orientações sexuais como: i) a homossexualidade: atração sexual e afetiva pelo mesmo sexo/gênero; ii) a bissexualidade: atração sexual e afetiva pelo mesmo sexo/gênero e pelo sexo/gênero oposto. Para Bento (2008, p. 32), "as reiterações que produzem os gêneros e a heterossexualidade são marcadas por um terrorismo contínuo", pois causam dor, sofrimento e exclusão dos corpos que divergem da "normalidade" e são caracterizados por conflitarem com as normas de gênero. A autora (2008) ainda conclui que:

A bicha, o sapatão, o afeminado, o transexual são essenciais para realimentar a heterossexualidade, por não serem estranhos, externos a ela, mas porque constitui (...) a diferença que gera aquilo que ela proíbe, tornando possível a própria coisa que ela torna impossível. (BENTO, 2008, p.32)

Então, torna-se indispensável compreender que a identidade de gênero, entendida como o gênero com o qual a pessoa se identifica (JESUS, 2012), pode ou não concordar com o gênero e o sexo ao qual foi atribuído a si, no nascimento, trazendo à tona a experiência transexual caracterizada pela pessoa que vivencia a identidade de gênero em desacordo com o sexo definido ao nascer, o que leva a caracterizar como

uma experiência identitária, que está relacionada à capacidade dos sujeitos construírem novos sentidos para os masculinos e femininos. É uma das múltiplas expressões identitárias que emergiram como uma resposta inevitável a um sistema que organiza a vida social fundamentada na produção de sujeitos "normais/anormais" e que localiza a verdade das identidades em estruturas corporais (BENTO, 2008, p.19-20).

O corpo transexual representa a contradição e a queda de um sistema de gênero binário e heterossexual, comprovando a partir de sua existência a possibilidade de refutação da heteronormatividade compulsória. Provando não ser a mesma, uma origem natural que funda os corpos e sim uma tecnologia social, evidenciando a possibilidade da ruptura das normas e expressões de gênero, que a partir da perfomatividade desses corpos confirma-se a possibilidade de outras formas de existências e vivências da sexualidade e do gênero, para além do masculino e feminino, pois o "gênero é internamente instável, e a vida dos transgêneros é uma evidência da quebra de quaisquer linhas de determinismo causal entre sexualidade e gênero" (BUTLER, 2014, p.270).

A existência da transexualidade e de outras experiências transitórias entre os gêneros mostram que não se há obrigação de cumprir a norma colocada e destinada aos corpos, mas que "existem corpos que escapam ao processo de produção dos gêneros inteligíveis, e ao fazê-lo se põem em risco porque desobedecem às normas de gênero; ao mesmo tempo, revelam as possibilidades de transformação dessas mesmas normas" (BENTO, 2008, p.31). Essas normas encaixam, modelam e doutrinam os corpos em nossa sociedade e a todo momento reprimem outras possibilidades de existências e vivências do gênero e da sexualidade.

A teoria "queer", surgida como um impulso crítico em relação à ordem sexual contemporânea (MISKOLCI, 2013), traz à tona a necessidade de despatriarcalizar as relações sociais e de se pensar a estrutura do gênero como algo cultural, dando espaço para se discutir a possibilidade e emergência de 
um gênero fluído, diverso e performático, que coloca em xeque toda uma construção identitária pautada na heterossexualidade compulsória, permitindo outros olhares sobre a sexualidade.

Dessa forma, para Butler (2003, p. 53), a "construção de uma identidade sexual coerente, em conformidade com o eixo disjuntivo feminismo/masculino, está fadado ao fracasso", pois a partir da visibilidade de outras maneiras de vivência e expressões de gênero e da sexualidade a sociedade entenderá que a heterossexualidade não é a única maneira de viver e existir em sociedade.

Pensar o gênero a partir da teoria queer é refutar a noção de "verdade" do sexo, produzida precisamente pelas práticas reguladoras que geram identidades por meio da matriz de normas de gênero coerentes (BUTLER, 2003), confrontando toda e qualquer norma que encaixe o indivíduo na tríade "sexo, gênero e heterossexualidade", pois, a matriz cultural por intermédio de qual a identidade de gênero se torna inteligível exige que certos
tipos de "identidade" não possam "existir" - isto é, aquelas que o gênero não decorre do sexo e
aquelas em que as práticas do desejo não "decorrem" nem do "sexo" nem do "gênero". (BUTLER,
2003, p. 39).

A teoria queer ajuda a pensar sobre os discursos, as experiências e vivências de pessoas que sofrem o estigma da humilhação social, estas frequentemente violentadas material e simbolicamente por não se adequarem a uma normatividade de gênero compulsória. Segundo Oliveira (2017, p. 116), "encontramos aqui outro paralelismo com o movimento queer - ir entender os processos de heterossexualização do mundo e desconstruí-los" (OLIVEIRA, 2017 p. 116), sendo necessário, a partir deste processo, superar a ideia de que a sociedade apenas se divide na binaridade hétero/homossexual. É importante extrapolar tal debate, "à medida que habilita as pessoas transexuais e travestis, as drag queen, os drag king, as lésbicas, os gays, os bissexuais, enfim, os designados pela literatura médica ou pelas ciências psi como sujeitos transtornados, enfermos, psicóticos, desviados, perversos" (BENTO, 2008, p. 41), dando espaço para o "existir" dessas pessoas em sociedade, contrapondo-se a cada momento ao terrorismo cultural que prega a hegemonia da heterossexualidade visibilizando assim os corpos "diferentes" e mostrando a possibilidade da diversidade sexual e de gênero;.

Portanto, pode-se pensar o queer como uma reação, uma oposição a tudo que é considerado normativo. Tal conceito vem priorizar uma diversidade de práticas e vivências, um estilo de vida que traz à tona múltiplas existências, pertencimentos e identidades tanto sexuais como de gênero, propondo, desse modo, a perspectiva de que não "existe diferença sexual, mas uma multidão de diferenças, uma transversalidade de relações de poder, uma diversidade de potências de vida" (OLIVEIRA, 2017, p. 124).

\section{PRESSUPOSTOS METODOLÓGICOS DA PESQUISA}


Inicialmente, vale mencionar que a pesquisa da qual originou este escrito foi aprovada pelo Comitê de Ética e Pesquisa da Universidade Federal de Sergipe, sob o parecer de número 187392, e seguiu a resolução do Conselho Nacional de Saúde de n 466 de 12 de dezembro de 2012 que versava sobre as diretrizes e normas regulamentadoras de pesquisas envolvendo seres humanos. $\mathrm{O}$ roteiro de entrevista utilizado foi previamente aprovado pelo referido comitê antes do início das atividades de campo, como também fora informado a tod@s ${ }^{7}$ participantes sobre os riscos e benefícios desta atividade para@s mesm@s.

O presente estudo se pauta sob a abordagem qualitativa por "considerar a necessidade de um conjunto de técnicas interpretativas para expressar o sentido dos fenômenos sociais e a compreensão dos significados das ações e relações humanas" (DIAS, 2014, p. 32). Outro aspecto relevante da abordagem qualitativa é que ela se aproxima da perspectiva dos estudos culturais, nos quais os estudos sobre corpo, gênero e diversidade sexual também se inserem.

Como estratégia de coleta de dados utilizou-se a entrevista narrativa. "As entrevistas não permitem dizer uma ou a verdade sobre as coisas e os fatos, mas pode considerá-las como a instância central que, somada as outras, traz informações centrais acerca do vivido" (ANDRADE, 2014, p. 176). Com base na entrevista narrativa, foi possível a apropriação das experiências d@s participantes na medida em que foi possível abordar

os aspectos objetivos/subjetivos, expressões do movimento individual e coletivo, sinais de uma organização social historicamente constituída em que as divisões de classe formam o pano de fundo de uma trama em que se geram as diferenças", numa cumplicidade dialética que favorece a construção de identidades de gênero (DIAS, 2014, p.37).

A entrevista narrativa foi utilizada para melhor estruturar o objetivo de analisar o banheiro como espaço político de gênero, como já mencionado. Perpetradas todas as entrevistas, foi feita a transcrição de todas as falas e narrativas para melhor leitura e compreensão das experiências d@s participantes. Foi lido com atenção todo o material obtido nas entrevistas e foram selecionadas as falas d@s participantes que se aproximavam e se distanciavam de nosso objetivo/problemática. A partir dessa seleção, foi feita a identificação de trechos dos discursos mais potentes para utilização no texto da pesquisa.

O campo empírico desse trabalho foi o campus São Cristóvão, Itabaiana, Laranjeiras da Universidade Federal de Sergipe (UFS). A UFS não possui em seu Sistema de Gerenciamento Acadêmico (SIGAA) o registro do quantitativo de pessoas transexuais, sendo assim, a sondagem foi realizada a partir da procura d@s participantes por meio do contato com estudantes que tinham mais proximidades com @s interessad@s. Outrora, é de suma importância colocar que tod@s @s entrevistad@s autorizaram a divulgação de suas identidades e nomes sociais.

As entrevistas foram realizadas no período de abril a junho de 2017. @s participantes foram estudantes transexuais matriculad@s em cursos de graduação da UFS. Com relação à distribuição por

\footnotetext{
${ }^{7}$ Ao longo do texto, utilizamos a grafia “@” em lugar dos artigos o/a, por estes fixarem o gênero em duas vertentes somente, desconsiderando outras possibilidades de viver e estar no mundo.
} 
campus vale salientar que d@s sete participantes matriculadas na UFS, cinco são estudantes do campus São Cristóvão, um de campus de Itabaiana e um do campus de Laranjeiras. No campus da cidade de Lagarto e Aracaju não encontramos nenhum(a) estudante transexual na fase da coleta de dados.

Para informar ao/à leitor/a, passou-se a destacar algumas característas d@s participantes, para contextualização de suas narrativas e experiências de socialização.

Entrevistada 1: A primeira entrevistada tem 44 anos de idade, natural do município de Santa Rosa de Lima/SE. A entrevistada identifica-se como uma mulher transexual, de orientação sexual heterossexual e cor parda. Ativista LGBT e militante da causa Trans, coordena a AMOSERTRANS Associação e Movimento Sergipano de Transexuais e Travestis. A ativista ingressou no ensino superior em 2013 após sua participação do ENEM - Exame Nacional do Ensino Médio, no curso de Letras Português/Francês, sendo pioneira nas discussões acerca do uso do nome social para pessoas trans na Universidade, o que culminou na efetivação da Portaria de Nome Social em todos os espaços da UFS, sendo então a primeira a utilizar tal política e ter seu nome social nos registros acadêmicos da UFS.

Entrevistado 2: Com 28 anos de idade, natural de Aracaju/SE, considera-se de etnia branca e, quanto à sua orientação sexual, heterossexual. Militante e ativista LGBT, faz sua militância específica na defesa dos direitos dos homens trans, participa de eventos, seminários e outros espaços como palestrante, participa das atividades da AMOSERTRANS e também coordena a Semana da Visibilidade Trans de Sergipe, que acontece na UFS, espaço onde se reconheceu militante e ativista trans. Ingressou no curso de Ciências Biológicas da UFS no ano de 2006, tendo no ano de 2011 solicitado transferência interna para o curso de Farmácia.

Entrevistado 3: Estudante do curso de matemática, natural de Salvador/BA, o terceiro entrevistado tem 25 anos e é negro. Participou do ENEM e ingressou no curso superior de licenciatura em matemática e, assim mudou-se para Aracaju, momento em que se viu mais liberto para assumir seu gênero e sexualidade. Assumiu-se transexual somente no Ensino Superior, a partir do contato com os coletivos e a Semana da Visibilidade Trans, mas não participa de espaços de militância e ativismo, preferindo viver no anonimato e seguir sua vida normalmente como qualquer pessoa.

Entrevistada 4: A quarta entrevistada tem 19 anos de idade e é de etnia parda. Natural de Aracaju/SE, considera-se heterossexual e se autodenomina uma pessoa reprimida e tímida. No ano de 2016, ela participou do ENEM e ingressou no curso de Biologia na UFS. Ao chegar à academia, participou da Semana da Visibilidade Trans e conheceu a militância LGBT e trans de Sergipe. A partir disso começou a participar de coletivos e espaços que discutem a temática, e em seguida a esse contato assumiu sua transexualidade um ano depois de seu ingresso na universidade.

Entrevistada 5: Militante e ativista LGBT, estudante de Teatro, tem 24 anos, é heterossexual e se declara negra. Natural de Salvador/BA, cidade onde iniciou e concluiu seus estudos básicos. A estudante de teatro é funcionária pública da prefeitura de Aracaju e a primeira atriz trans do estado de 
Sergipe. Milita no movimento LGBT, participa da organização da Semana da Visibilidade Trans que acontece anualmente na UFS, participa de coletivos e espaços de discussão da temática Gênero e Diversidade Sexual na universidade e é defensora das causas Trans, além de ser integrante da Associação de Travestis Unidas na Luta, onde já lecionou cursos e oficinas na área de teatro para o público LGBT. Ela diz que depois da vivência universitária decidiu assumir sua transexualidade e a Universidade foi um espaço importante nessa tomada de decisão.

Entrevistada 6: Natural da cidade alagoana de Pão de Açúcar, com 23 anos de idade, a transexual Victória se define, no que toca à orientação sexual, como uma pessoa heterossexual e de etnia negra. Prestou o Exame Nacional do Ensino Médio - ENEM e em 2016 consegue ingressar no curso de Museologia do Campus de Laranjeiras na Universidade Federal de Sergipe.

Entrevistada 7: Primeira estudante trans do Campus de Itabaiana, heterossexual de 28 anos de idade, ingressou na UFS no ano de 2012, a partir do último vestibular oferecido pela instituição no curso de licenciatura Letras Vernáculas. Da mesma forma que @s demais, ela é mais uma pessoa que borra a norma e perpassa os corredores da UFS de Itabaiana causando estranhamento, indagações e provando a possibilidade da presença trans no Ensino Superior.

\section{OS USOS POLÍTICOS DO CORPO: BANHEIRO E TRANSEXUALIDADE}

Me senti no lugar errado, sabia? Tipo, bem mal, me senti bem mal, foi o "diazinho" pior da minha vida porque era para ter sido um dia legal, que o trote é legal, né. Geralmente as pessoas ficam felizes e tal, rola pintura essas coisas e tal e daí tipo você se vê obrigado a adentrar no banheiro que não é teu porque tu não tem um corpo que você gostaria de ter (ENTREVISTADO 3, 2017).

Os usos do corpo implicam uma territorialização política dos espaços. A narrativa acima exemplifica a problemática dos usos públicos dos banheiros pautadas em políticas que têm em sua base o binarismo histórico de gênero. $O$ relato deixa transparecer as dificuldades encontradas por parte $d @ s$ estudantes transexuais da UFS no que tange ao direito ao uso do banheiro. O entrevistado expõe o constrangimento ao chegar na universidade no momento do "trote dos calouros", onde foi empurrado pelos colegas de classe junto com outras meninas no banheiro feminino. A situação não o deixou confortável, pois se sentiu num espaço que não era dele, já que sua identidade de gênero é masculina, porém, seu corpo "biológico de mulher" o colocou nesta situação constrangedora.

No que tange ao uso do banheiro, aqui visualizamos que o corpo trans é um corpo que protesta, pois é um corpo que não consegue visualizar um lugar onde sua "subjetividade" seja contemplada. A subjetividade é constituída por posições e essas posições não são meros produtos teóricos, mas princípios organizadores totalmente imbuídos de práticas materiais que produzem um "sujeito" viável (BUTLER, 1998). Frente à política que exige um sujeito "universal", os corpos trans que se constrangem frente a um banheiro clamam contra seu apagamento singular. Entrar num banheiro feminino tendo um corpo biológico masculino é ir contra as formas de regulação de comportamento que a mesma dita; é denunciar algo que não os representa. Nesta situação, o que está evidente é que o 
corpo trans reivindica pensar os corpos pela questão da diferença, que existem outros modos para se pensar as relações entre gêneros: pensando a diferença na diferença.

Assim como o Entrevistado 3, outra narrativa semelhante foi a fala da Entrevistada 6 que logo na primeira semana deu aula também passou por problemas em relação ao uso desse espaço:

Na primeira semana, quando eu entrei, fui barrada no banheiro feminino [...] para mim foi um choque porque eu achava que era um ambiente que não existia preconceito, tipo assim, você está numa universidade [...] um dos lugares que eu mais sofro preconceito é na universidade.

A entrevistada deixa manifesta sua indignação ao perceber que na universidade a reprodução da heterossexualidade ainda é uma realidade. Segundo Bento (2008, p.30), "o sexo é uma das normas pelas quais se torna viável qualificar a humanidade corpórea", é a partir do sexo que a sociedade qualifica os corpos, deste modo, os corpos trans, vistos sob a lente hegemônica da heteronormatividade entram em conflito quando reivindicam o acesso ao banheiro, por não estarem inteligíveis à norma. Sob este viés, Butler (2003, p.39) menciona que a matriz cultural pela qual a identidade de gênero se torna inteligível exige que certos tipos de 'identidade' não possam existir - isto é, aquelas em que o gênero não decorre do sexo e aquelas em que as práticas do desejo não decorrem nem do sexo e nem do gênero, que é o caso dos corpos trans e de outras expressões de gênero divergentes da heterossexualidade e da tríade sexo-gênero-prática sexual.

Outra fala que caracteriza essa dificuldade em se sentir aceito no banheiro é a fala do Entrevistado 2 que, ao ser perguntado sobre sua experiência, sobre o assunto, relatou:

\begin{abstract}
Banheiro eu evitava, sempre evitei, mas tinha momentos que não dava, a gente passa o dia todo na universidade, não tem como não ir ao banheiro. Então... eu sempre chamava os meus amigos homens para irem comigo aí eles olhavam e a gente entrava. Se tivesse muita gente já me incomodava, se tivesse vazio eu usava! Era assim e eu sempre tentei ir acompanhado e quando não dava eu usava o banheiro do meu departamento que é mais tranquilo (ENTREVISTADO 6 , 2017).
\end{abstract}

O Entrevistado, ao citar da necessidade de convidar os amigos "homens" para ir ao banheiro, coloca a estratégia encontrada para não sofrer processos de opressão e discriminação quanto ao uso do banheiro. A narrativa dele nos leva a perceber o quanto os espaços da universidade também podem reproduzir a heteronormatividade e o binarismo de gênero hegemônico em nossa sociedade outrora, estas normas podem ser também escritas em espaços arquitetônicos, como o banheiro, entre outros, assim como cita Miskolci (2013, p. 41). O banheiro público é uma tecnologia de gênero, que merece ser repensada. Divisões arquitetônicas são
algumas das formas que a sociedade encontra de colocar cada um no seu 'quadrado' e, sobretudo, no
caso do banheiro, no seu lugar dentro do binário masculino e feminino.

Neste sentido, vale salientar que, devido à reprodução da heteronormatividade compulsória em nossa sociedade, os espaços sociais e arquitetônicos são também construídos a partir deste padrão hegemônico que demarca os corpos a partir de sua materialidade sexual biológica. Ao discutir o espaço arquitetônico como tecnologia de gênero, podemos perceber que não há espaço para 
expressões que não coadunem com a matriz cultural heteronormativa e binária na universidade, pois, neste espaço, as posições masculinas e femininas são instituídas a partir de normas que regulam e determinam a impossibilidade de existência fora de seus moldes. Tal regulação "suprime a multiplicidade subversiva de uma sexualidade que rompe as hegemonias heterossexual, reprodutiva e médico-jurídica" (BUTLER, 2003, p. 41).

Durante a pesquisa ficou notório, através das entrevistas narrativas, que @s alun@s transexuais, frente à problemática da utilização dos banheiros, adotavam estratégias de resistência para se colocar frente a essa proibição, como podemos perceber na fala da Entrevistada 6:

Eu sempre ia com alguém para servir de testemunha para mim, só que nesse dia como eu estava muito apertada eu mandei um amigo meu esperar na porta e ele me esperou. E graças à Deus ele viu a pessoa que me barrou e serviu de testemunha para mim.

A partir do relato da Entrevistada 6 e dos demais relatos dessa pesquisa chegou-se à conclusão que, assim como cita Bento (2008, p. 42), "a ordem arquitetônica são tecnologias de construção de gênero, de discriminação". No entanto, o corpo trans, por estar em desacordo com a regra escrita nas placas de identificação dos banheiros, ao continuar adentrando esse espaço, demonstra atitude de resistência: assim como o Entrevistado 2, a Entrevistada 6 usa da mesma estratégia, que é a de levar alguém consigo quando precisa usar o banheiro.

Aqui, fica expressado o protesto em nível de questionamento e repúdio contra uma premissa fundamentalista que constrói um sujeito que serve e é eficaz para uma política rigidamente programática. Na UFS, o corpo trans que adentra o banheiro é um corpo que tenta se deslocar de forma intencional em meio às relações de poder, fazendo com que os efeitos instituídos pela "norma" não sejam unilineares quanto a sua direção e, desta forma, escapem desse "jogo" de operações materiais e simbólicas.

No entanto, podemos perceber que estas situações são uma constante na vida d@s estudantes trans, como descreve a Entrevistada 4, em seu relato:

Com relação aos banheiros eu sempre vou sozinha com meus fones de ouvido já para não escutar nada, porque a gente sabe que existem garotas que tem uma mente fechada, que não entendem, que riem... Um dia aconteceu algo que eu não percebi por conta de meus fones, mas que foi um caso de transfobia no banheiro do restaurante universitário. Eu entrei no banheiro e eu estava com os meus fones e eu não escutei, só que umas amigas minhas de enfermagem disseram que as meninas saíram do banheiro e ficaram rindo e falando de mim lá fora, esperando eu sair do banheiro pra poderem entrar.

As entrevistadas 4 e 6 se utilizaram de estratégias para utilizarem o banheiro e, de certa forma, resistir ao controle feito pela instituição/comunidade universitária em relação aos usos de seus corpos, tidos como desviantes e não detentores do direito ao uso do banheiro. Para zelarem pela sua integridade, elas fazem uso da ajuda de amig@s para observar enquanto utilizam o banheiro. A entrevistada 4, de forma mais eloquente, entra e prefere não perceber as falas discriminatórias sobre a sua presença no banheiro, fazendo uso dos fones de ouvido para abstrair a discriminação. 
Outra estratégia é a atitude da Entrevistada 7, que utiliza da afirmação de sua identidade como resistência aos olhares proibitivos das estudantes quando a mesma adentra para retocar sua maquiagem.

\begin{abstract}
Eu não tenho o hábito de estar toda hora no banheiro, nunca tive! Mas claro que tem dias que a gente precisa ir no banheiro, a gente precisa olhar o cabelo né, ajeitar a maquiagem. Toda mulher precisa disso, né. Um dia, eu fui entrar no banheiro e as meninas que estavam comigo perguntaram: você vai entrar em que banheiro? E eu respondi: Eu vou entrar no banheiro feminino, sou mulher eu tenho que entrar no banheiro feminino. Aí eu entrei e elas disseram: Não, você não pode entrar no banheiro feminino não! E então eu indaguei: Não? Porque não? E elas responderam: Não porque o banheiro masculino é do outro lado. Eu então virei e disse: É, realmente, o banheiro masculino é do outro lado. Neste momento, chega o segurança. Aí eu disse a ele, você que é segurança, você pode usar o banheiro masculino que você é homem, eu imagino, você está vestido como homem, eu imagino que você seja homem, você pode usar do outro lado. Eu sou mulher e eu vou usar esse. E ele respondeu: Mas não pode! Eu disse: Então venha me tirar. Aí simplesmente eu entrei. Agora todo lugar a partir desse dia eu vou no banheiro feminino. As outras mulheres olham, ficam meio assim, acham estranho né por eu estar no banheiro feminino. Mas eu não levo com muita naturalidade isso, até porque é uma das pequenas coisas que eu já enfrentei na vida e não morri.
\end{abstract}

A discussão acerca do uso banheiro leva a perceber o quanto a sociedade ainda opera a partir do binarismo heterossexual masculino/feminino em consonância com o sexo biológico. Tal discussão leva a perceber que na sociedade, assim como coloca Oliveira (2017, p. 143), "não há espaço para homens que são/estão femininos nem para mulheres que são/estão masculinas', o que implica uma ausência de espaços para pessoas que não fazem o gênero "homem" nem fazem o gênero "mulher". Logo, o corpo trans, esse performático, adentra nessa posição de um corpo não aceito e não incluído em diversos espaços, sejam eles arquitetônicos ou não, da sociedade. Como é o caso da Entrevistada 7, que foi interpelada pelo segurança da instituição pois, segundo ele, ela estaria usando o banheiro errado, momento em que respondeu ela que estava no banheiro correto, posto que ela era uma mulher.

Lutar e evadir-se dessas representações caracteriza aquilo que escapa às normas, evidenciando fissuras, fossos e mostrando as instabilidades dessa construção (BUTLER, 2010). Fugir dessa formação identitária de gênero, como mostra Butler (2010), é como se os corpos, que fogem da norma, não fossem legitimados fora delas; é como se estes corpos formassem um campo de deformação, pois vão contra a norma ou forma regulatória de ser e de se expressar. São corpos que não se enquadram na inteligibilidade da cultura, já que toda inteligibilidade implica sistemas categoriais ou taxionômicos metafísicos responsáveis por organizar a realidade material. Quando algo não compõe o campo simbólico da cultura, será considerado um risco, um desvio, algo excluído das categorias e, portanto, da metafísica social dos sujeitos.

Porém, percebe-se que nem todas @s estudantes trans participantes da pesquisa tomaram como forma de resistência o embate direto com a proibição, o Entrevistado 3 e o Entrevistado 2 preferiram, diante do medo da possibilidade eminente do preconceito, utilizar outra estratégia. Vejamos:

Tinha um banheiro que ficava numa didática nova, nunca tem ninguém naquele banheiro. É um banheiro que tu entra e aí tu tem masculino e feminino no mesmo banheiro. Então eu costumava sempre ir nesse banheiro porque sabia que nunca teria ninguém e que eu podia ir ali. Entendeu? (ENTREVISTADO 3, 2017). 
Eu sempre chamava os meus amigos homens para irem comigo aí eles olhavam e a gente entrava. Se tivesse muita gente já me incomodava, se tivesse vazio eu usava. Era assim, eu sempre tentei ir acompanhado. Quando não dava eu usava o banheiro do meu departamento, que é mais tranquilo, porque todas as pessoas ali sabem que eu sou trans e eu não teria nenhum problema em encontrar qualquer pessoa dentro do banheiro. Ali nesse espaço já me conheciam, então o banheiro mais confortável para eu ir era sempre o banheiro do meu departamento. (ENTREVISTADO 2, 2017).

A relação da transexualidade e a necessidade do uso do banheiro público na universidade mostram o quanto ainda, através da reprodução da heteronormatividade nos espaços arquitetônicos nesse caso, o banheiro -, tenta-se controlar e produzir a heterossexualidade. Percebe-se nesses espaços as inscrições históricas das normas e padrões heterossexuais inteligíveis, as pessoas aceitas têm de expressar seu gênero em conformidade com o sexo biológico e prática sexual. Desse modo, não sobra espaço para os corpos que divergem dessa estrutura, representando o corpo trans, os quais demonstram perigo para essas normas na medida em que reivindica o gênero em discordância com o corpo sexuado (BENTO, 2008), e assim corroborando com a segregação do acesso das pessoas trans aos banheiros por simplesmente subverterem a norma. A partir do momento em que corpos e gêneros fogem dos limites simbólicos demarcados, são considerados não legítimos, ou seja, anormais. Porém, como destaca Alós (2012), os corpos que ultrapassam esses limites dão margem e brechas para questionar a própria noção do que é acatado como culturalmente legítimo.

A partir de formas de gênero que transcendem o binarismo prescrito pela matriz heterossexual, essas identidades de gêneros subversivas abrem fissuras para desestabilizar as amarras que prendem os corpos na inteligibilidade estrutural dessa matriz ou modelo racional, ocasionando uma ressignificação subversiva de corpo, sexo e gênero (ALÓS, 2012), abrindo as portas da própria estrutura/matriz.

Neste sentido, para a superação da demarcação e governo de gênero, Butler (2003) sugere que a política se desloque no sentido não mais de estabelecer um sujeito de identidade fixa, mas que deixe em aberto a questão da identidade, que ela seja algo que não organize a pluralidade, mas que a mantenha aberta sob permanente vigilância.

Se as identidades deixassem de ser fixas como premissas de um silogismo político, e se a política não fosse mais compreendida como um conjunto de práticas derivadas dos supostos interesses de sujeitos prontos, uma nova configuração política surgiria (BUTLER, 2003). Uma política menos programática e, portanto, mais atenta às dinâmicas das realidades sociais, culturais, política e econômicas que surgem enquanto problemas no campo das relações humanas.

\section{CONSIDERAÇÕES FINAIS}

Retomando o objetivo de nosso artigo, que foi analisar o banheiro como espaço político de gênero a partir dos corpos de estudantes transexuais da Universidade Federal de Sergipe (UFS), entende-se que corpo do outro e o meu próprio são enigmas que oferecem pistas, indícios, signos, sintomas que desconstroem todo tipo de taxonomia e, portanto, o contexto cultural que a sustenta. 
Nessa desconstrução taxionômica, o exercício de desconstruir não deve ser visto como sinônimo de censura ou aniquilamento, pelo contrário, trata-se de se libertar de amarras epistêmicas e metafísicas para que os sentidos de gênero não fiquem presos a uma matriz antecipatória que não deixe emergir outros significados. É um desafio no sentido de emancipar o gênero de ontologias que os condenam a matrizes de demarcação e governo (ZOBOLI et al, 2015).

As políticas que normatizam os usos do corpo em espaços públicos necessitam desestabilizar as normas de gênero impostas pela heterossexualidade, e, por esta pedagogização arbitrária, faz-se necessária a desconstrução de valores historicamente construídos pela sociedade, tratando de pensar uma nova política de gênero que possa refletir sobre tais valores e visibilizar os invisíveis. É urgente discutir o entendimento das normas e diretrizes que correspondam às expectativas da regulação dos corpos a partir de um modelo social, que através da heterossexualidade controla e produz o gênero.

Para Butler (1998), dentro do contexto político contemporâneo, talvez seja especialmente urgente sublinhar a própria categoria do "universal" como lugar de insistente disputa e ressignificação. Tendo em vista o caráter contestado do termo, supor desde o início uma noção instrumental ou substantiva do universal é impor uma noção culturalmente hegemônica sobre o campo social. Sendo assim, sugere-se: "banheiro universal já!".

\section{REFERÊNCIAS}

1. ALÓS, A. P. A letra, o corpo e o desejo: masculinidades subversivas no romance latino-americano. Florianópolis: Mulheres, 2012.

2. ANDRADE, S. S. A entrevista narrativa ressignificada nas pesquisas educacionais pós estruturalistas. In: Metodologias de pesquisas pós críticas em educação, Organização: Dagmar Estermann Meyer \& Marlucy Alves paraíso. Belo Horizonte: Mazza Edições 2014.

3. ANDRADE, L. Travesti na Escola: Assujeitamento e/ou Resistência a Ordem Normativa 240 f. Tese (Doutorado em Educação) - Programa de Pós-Graduação em Educação da Universidade Federal do Ceará, Fortaleza, 2012.

4. BENTO, B. A. M. O que é transexualidade. São Paulo, Brasiliense. 2008. Regulações de gênero. Cadernos Pagu, Campinas, v. 42, p. 250-274, 2014.

Corpos que pesam: sobre os limites discursivos do "sexo". In: LOURO, G. L. O corpo educado: pedagogias da sexualidade. Belo Horizonte: Autêntica, 2010 p. 151-172.

Problemas de gênero: feminismo e subversão da identidade. Tradução de Renato Aguiar. Rio de Janeiro: Civilização Brasileira, 2003. 
8. Aires: Paidós, 2002.

9. Campinas, v. 11, p. 11-43, 1998.

10. CARVALHO, M. E. P.; et al. Direitos Humanos das mulheres e das pessoas LGBTQI: inclusão da perspectiva da diversidade sexual e de gênero na educação e na formação docente. João Pessoa: EDUFPB, 2016.

DIAS, A. F; CRUZ, M. H. S. A produção/reprodução do corpo generificado na escola. Cadernos de Pesquisa, v. 22, n.3, pp.25-41, 2015.

DIAS, A. F.; CARVALHO, M. E. P.; OLIVEIRA, D. A. O processo de inclusão/exclusão de uma professora transexual. Revista da FAEEBA - Educação e Contemporaneidade, Salvador, v. 25, n. 45, p. 145-158, jan./abr. 2016.

13. FRANCO, N.; CICLINI G. A. Professoras trans brasileiras em seu processo de escolarização. Estudos Feministas, Florianópolis, 23(2): 325-346, maio-agosto/2015.

14. FRANCO, N. Professoras trans brasileiras: ressignificações de gênero e sexualidades no contexto escolar. . 265f. Tese (Doutorado em Educação) - Programa de Pós-Graduação em Educação da Universidade Federal de Uberlândia, Uberlândia, 2014.

15. JESUS, J. G. Identidade de Gênero e Políticas de Afirmação Identitária, Anais VII Congresso Internacional de Estudos sobre a Diversidade Sexual e de Gênero da ABEH, Salvador, 2012. ISSN: 2316-3844.

16. JAEKEL, K. S.; NICOLAZZO, Z. Teaching trans*: Strategies and tensions of teaching gender in student affairs preparation programs. Journal for the Study of Postsecondary and Tertiary Education, 2, 165-179, 2017. DOI: 10.28945/3859.

LONGARAY, D. A.; COSTA RIBEIRO, P. R. Espaços educativos e produção das subjetividades gays, travestis e transexuais. Revista Brasileira de Educação, Rio de Janeiro, v. 20 n. 62, p. 723747, jul./set. 2015. http://dx.doi.org/10.1590/S1413-24782015206209.

18. MILNER, J-C. Por una política de los seres hablantes: breve tratado político II. - I ed. - Olivos: Grama Ediciones. 2013. 
MISKOLCI, R. Teoria Queer: um aprendizado pelas diferenças; 2. ed. rev. e ampl., 1. reimp. - Belo Horizonte: Autêntica Editora, 2013.

NICOLAZZO, Z. Compulsory heterogenderism: A collective case study. NASPA Journal About Women in Higher Education, 10(3), 245-261, 2017. DOI: 10.1080/19407882.2017.1351376.

OLIVEIRA, J. M. Limbos da Normatividade: Reflexões sobre o gênero humano nas experiências de cross dressing (p.141-156). In: Géneros e sexualidades: Interseções e Tangentes, Organização: João Manuel Oliveira \& Lígia Amâncio. Fundação para a ciência e tecnologia, Ministério da Ciência, Tecnologia e Ensino Superior, Brasil: Gráfica Maiadouro, 2017.

22. PEREIRA, M. M. Fazendo género no recreio: a negociação do género em espaço escolar. Lisboa: ICS - Instituto de Ciências Sociais, 2012.

PRECIADO, P. B. Manifesto Contrassexual. São Paulo: N-1 Edições, 2014.

REIDEL, M. A pedagogia do salto alto: histórias de professoras transexuais e travestis na educação brasileira. 2013. 147 f. Dissertação (Mestrado em Educação) - Programa de PósGraduação em Educação, Universidade Federal do Rio Grande do Sul, Porto Alegre: 2013.

SANTOS, A. L. Formação de pessoas transexuais na Universidade Federal de Sergipe: enfrentamento e resistência às normas de gênero no espaço acadêmico. 2018. 98 f. Dissertação (Mestrado em Educação) - Programa de Pós-Graduação em Educação, Universidade Federal de Sergipe, São Cristóvão, 2018.

26. SCOTT, J. Gênero. Uma categoria útil de análise histórica. Educação e Realidade. 16(2) julho/dezembro.1990.

27. SEFFNER, F.; REIDEL, M. Professoras travestis e transexuais: saberes docentes e pedagogia do salto alto. Currículo sem Fronteiras, Pelotas, v. 15, n. 2, p. 445-464, maio/ago. 2015.

28. SILVA JUNIOR, J. A. Direitos à meia luz: regulamentação do uso do nome social de estudantes travestis e transexuais nas instituições escolares. Revista da FAEEBA - Educação e Contemporaneidade, Salvador, v. 25, n. 45, p. 173-189, jan./abr. 2016. Cristóvão, 2013. 
30. TORRES, M. A.; PRADO, M. A. Professoras Transexuais e Travestis no Contexto Escolar: entre estabelecidos e outsiders. Educação \& Realidade, Porto Alegre, v. 39, n. 1, p. 201-220, jan./mar. 2014.

31. VERGUEIRO, V. Por inflexões decoloniais de corpos e identidades de gênero inconformes: uma análise autoetnográfica da cisgeneridade como normatividade. Dissertação (mestrado) Universidade Federal da Bahia, Instituto de Humanidades, Artes e Ciências Professor Milton Santos, Salvador, 2016.

32. ZOBOLI, F; CORREIA, E. S.; SILVA, R. I.; COSTA, T. R. A lei anti-gay russa: demarcações e governo dos corpos no mundial de atletismo 2013. Pensar a Prática, Goiânia, v. 18, n. 3, jul./set. 2015.

\section{Alfrancio Ferreira Dias:}

Doutor em Sociologia, Professor do Programa de Pós-graduação em Educação da Universidade Federal de Sergipe.

\section{Fabio Zoboli:}

Pós-doutorando em Educação do corpo pela Universidad Nacional de La Plata (UNLP) - Argentina. Doutor em Educação pela Universidade Federal da Bahia - UFBA. Professor do Departamento de Educação Física da Universidade Federal de Sergipe - UFS. Professor do Programa de Pós-graduação em Educação da UFS (PPGED). Membro do grupo de pesquisa "corpo e política".

\section{Adriana Lohanna dos Santos:}

Mestre em Educação pelo Programa de Pós-graduação em Educação da Universidade Federal de Sergipe, Ativista Trans e Professora de educação básica.

\section{Como citar este documento:}

DIAS, Alfrancio Ferreira; ZOBOLI, Fabio; DOS SANTOS, Adriana Lohanna. O BANHEIRO COMO ESPAÇO POLÍTICO DE GÊNERO. Reflexão e Ação, Santa Cruz do Sul, v. 26, n. 2, ago. 2018. ISSN 1982-9949. Disponível em: <https://online.unisc.br/seer/index.php/reflex/article/view/11734>. Acesso em: 16 ago. 2018. doi: http://dx.doi.org/10.17058/rea.v26i2.11734. 